\title{
INTENSITY OF NATURAL SELECTION FOR ODONTOMETRIC TRAITS GENERATED BY DIFFERENTIAL FERTILITY IN PEROMYSCUS LEUCOPUS
}

\author{
LARRY LEAMY \\ Department of Biology, California State University, Long Beach, \\ California 90840, U.S.A.
}

Received 2.xi.77

\begin{abstract}
SUMMARY
The effects of natural selection on the widths of the second $\left(\mathbf{M}_{2}\right)$ and third $\left(\mathrm{M}_{3}\right)$ mandibular molars in populations of Peromyscus leucopus were assessed by a comparison of fertile versus infertile individuals in each of three generations. Fertility was scored in an all-or-none fashion: those mated pairs producing any progeny were considered fertile whereas those failing to produce progeny in a specified period of time were considered infertile. Directional selection was evident only for the $M_{3}$ in the wild individuals; in all other combinations (of sex, generations, and molars), the variances of the infertile mice were greater than those for the fertile mice, indicating the presence of stabilising selection. Selection was more stringent both in the wild mice (compared to the laboratory-bred generations), and on the $\mathrm{M}_{3}$ compared to the $\mathrm{M}_{2}$. Overall, the mean intensity of selection on the molars was $0 \cdot 1$, and the mean change in relative fitness $(\Delta \bar{w} / \bar{w})$ was 2 per cent. It was postulated that selection was acting through a correlation with body size, although body weights were not taken on the mice and thus this hypothesis could not be tested. Stabilising selection for an optimal intermediate tooth row length (and width) was invoked to explain the fact that in all cases the interdental correlations in the infertile individuals were higher than those for the fertile individuals.
\end{abstract}

\section{InTRODUCTION}

Although the evolutionary literature abounds with studies demonstrating the existence of natural selection operative on a variety of quantitative characters, in few of these is the intensity of the selection estimated. The first adequate method for such an estimation was due to Haldane (1954), but since that time other more refined methods have been developed by several investigators (Marcus, 1964; Van Valen, 1965a, 1967; O'Donald, 1968, 1970 $a$ and $b, 1971)$. Generally these methods are based on a comparison of the basic statistics of the character of interest in "selected" and "unselected" segments of a population. Although both mortality and reproductive components obviously are involved in the selection process, in practice mortality has usually proved easier to assess, and thus in most previous studies the selected segment has represented the survivors from the original (unselected) cohort (Johnson, 1976). Characters which do not change with age, good examples of which are dental dimensions in mammals (Van Valen, 1963, 1965b), have proven especially useful in such studies.

Dental dimensions (widths of the second and third mandibular molars) were the characters used in a previous study (Leamy and Bader, 1970) involving fertile and infertile populations of Peromyscus leucopus. The infertile 
mice generally exhibited greater variances than the fertile mice throughout three generations, and this was taken to be evidence of the existence of natural (stabilising) selection. It was originally suggested that this selection was most probably mediated through a correlated character such as body size (Leamy and Bader, 1970), but since the age of the mice differed widely, body weights were not taken and thus this interpretation is speculative only. This paper is concerned primarily with the estimation of the intensity of selection, following the methods of O'Donald (1968, 1971, 1972), on the molar widths in these populations of mice. The estimates allow insight into the magnitude of selection which may be generated from fertility differences alone, and are interesting to compare with the more typical values obtained from mortaility differences.

\section{Materials AND methods}

The Peromyscus leucopus utilised in this study originated from 89 individuals (50 males, 39 females) which were trapped from the wild during the Fall of 1965 (Leamy and Bader, 1968). Thirty-three single pair matings of these wild (W) mice were made to produce the $F_{1}$ generation, each of 21 pairs eventually succeeding in producing one to three litters. Those pairs failing to produce progeny within 4 months from the time of mating were remated among themselves (some females also were mated with surplus males), and if 2 months later (total of 6 months) they still were unsuccessful in producing progeny, they were considered infertile. In most cases, however, they were allowed to remain in the cages up to 12 months before being sacrificed, so that 6 months should be considered as the minimal amount of time allowed for the testing of fertility.

Most (though not all) $\mathrm{F}_{1}$ progeny also were single-pair (and randomly) mated in order to produce the $\mathrm{F}_{2}$ generation. This time those pairs failing to produce progeny within a minimum of 4 months (rather than 6 months as before) from the time of mating were considered infertile. A total of 60 pairs of $F_{1}$ parents, six of the pairs consisting of $F_{1}$ females with original (wild) males, were successful in producing up to five litters each. Many of these $F_{2}$ progeny were eventually mated as above in order to produce the third and final generation. Again, failure to produce progeny after 4 months was the criterion for infertility. Fertile $F_{2}$ pairs (total of 131 ), seven of which consisted of $\mathrm{F}_{2}$ females and original (wild) males, were sacrificed after they had produced a minimum of four offspring each.

A total of well over 1000 mice from 212 families were produced, aided by a general trend of increased numbers per litter as well as numbers of litters/pairs throughout the three generations (Leamy and Bader, 1970). Originally three offspring were randomly chosen from each family in order to estimate the heritability (by regression of offspring on parents) of the widths of the second $\left(\mathrm{M}_{2}\right)$ and third $\left(\mathrm{M}_{3}\right)$ mandibular molars (Leamy and Bader, 1968). Thus, although all the wild mice were mated, many of the $F_{1}$ and $F_{2}$ (and all of the $F_{3}$ ) individuals were used as offspring only, and were not "tested" for fertility. In the present study, only those mice tested as parents (whether fertile or infertile) in each of the three generations, are considered.

Both the left and right $M_{2}$ and $M_{3}$ widths were measured in microns with a Gaertner travelling microscope. The mean of the two sides (rather 
than either single side) of each molar is used throughout the analysis, although it should be mentioned that the single sides exhibited trends virtually identical to that of the combined mean. Asymmetries (right minus left differences) also were examined, but showed no significant differences $(P>0.05)$ in either their means or variances in fertile versus infertile individuals throughout the three generations. The widths of the molars are essentially constant after eruption into the oral cavity, so that even though the age of the mice differed widely, growth was not a biasing factor.

Of the several methods available for the estimation of selection intensities of quantitative characters (see Johnson, 1976), those devised by O'Donald (1968, 1971, 1972) seemed most appropriate. Van Valen's methods $(1965 a, 1967)$ are based on a somewhat unrealistic truncation model in which the preselection distribution is necessarily assumed to be normal. O'Donald's formulations are more general, the shape of the preselection distribution being described by the second $(V)$, third $(\mu 3)$, and fourth $(\mu 4)$ moments about the mean. O'Donald $(1968,1970 a)$ has derived expressions for the intensity of selection $(I)$ assuming fitness decreases in proportion to the square of the deviation of the character from its optimum ("quadratic fitness function "):

$$
I=\frac{(\theta-\bar{X})^{2}+V}{\phi}
$$

where

$$
(\theta-\bar{X})=\frac{V^{2}(\Delta \bar{X})-\mu 4(\Delta \bar{X})+\mu 3\left[(\Delta \bar{X})^{2}+\Delta V\right]}{\left.2 V[\Delta \bar{X})^{2}+\Delta V\right]-2 \mu 3(\Delta \bar{X})},
$$

and

$$
\phi=\frac{2 V(\theta-\bar{X})-\mu 3}{\Delta \bar{X}}+(\theta-\bar{X})^{2}+V .
$$

Here $V=$ the variance of the character, $\Delta \mathbb{X}$ and $\Delta V$ represent the difference in the mean and variance, respectively, between the before and after selection segments (after minus before) of the population, and $\theta=$ the "optimum "value or class of the character.

This formula is quite valid for stabilising selection, or a combination of stabilising and directional selection. If only directional selection is present $(\Delta V=0)$, however, it is conceivable that the "optimum" value is not even present, and the above expression is not appropriate (O'Donald, 1968, $1970 a$ ). This expression also normally is not applicable if there is disruptive selection, for the model assumes that there is only one optimal class.

O'Donald (1970 $a$ and $b$ ) also has developed another expression for assessing the effect of selection. This expression is $V_{w} / \bar{w}^{2}$, where $V_{w}==$ the variance in relative fitness, and $\bar{\omega}^{2}=$ the square of the mean relative fitness. O'Donald $(1970 b)$ has shown that $V_{w} / \bar{w}^{2}=\Delta \bar{w} / \bar{w}$, so that this measure of selection describes the proportionate increase in mean fitness. The essence of Fisher's (1930) "Fundamental Theorem of Natural Selection" is that the rate of increase in fitness $(\Delta \bar{w})$ is equal to the genetic variance of fitness $\left(\Delta \bar{w}=V_{w} / \bar{w}\right.$, where $\bar{w}$ is standardised to 1$)$, so that the equation above represents a simple modification of this theorem.

At any rate, expressions for $\Delta \bar{w} / \bar{w}$ analogous to those for $I$ have been 
developed by O'Donald ( $1970 a$ and $b$ ) for the different fitness functions. For stabilising selection (or stabilising plus directional selection), and assuming a quadratic fitness function:

$$
\Delta \bar{w} / \bar{w}=\frac{\mu 4-V^{2}+4 V(\theta-\bar{X})^{2}-4 \mu 3(\theta-\bar{X})}{\left[\phi-(\theta-\bar{X})^{2}-V\right]^{2}}
$$

where the symbols are the same as before. For directional selection only with the quadratic fitness function, the third and fourth moments about the mean are not required (O'Donald, 1973):

$$
\Delta \bar{w} / \bar{w}=\frac{(\Delta \bar{X})^{2}}{V}+\frac{1}{2}\left[\frac{\left(\Delta \bar{X}^{2}\right)}{V}\right]^{2}
$$

\section{RESULTS}

The means (and sample sizes) of the widths of the $M_{2}$ and $M_{3}$ for the fertile and infertile mice of each sex in each of the three generations are presented in table 1. Sample sizes in some combinations for the separate sexes are slightly less than those given previously (Leamy and Bader, 1970)

\section{TABLE}

Means (expressed in microns) of the widths of the second $\left(M_{2}\right)$ and third $\left(M_{3}\right)$ mandibular molars for fertile (F) and infertile (I) mice of each sex for the wild-caught (W), $F_{1}$ and $F_{2}$ generations.

\begin{tabular}{|c|c|c|c|c|c|}
\hline Males & & \multicolumn{2}{|l|}{$W$} & $F_{1}$ & $\mathrm{~F}_{2}$ \\
\hline \multirow{2}{*}{$\mathrm{M}_{2}$} & $F$ & 042.8 & & $047 \cdot 6(46)$ & 041.1 (112) \\
\hline & $I$ & $\begin{array}{l}942.8 \\
956 \cdot 9\end{array}$ & (9) & $\begin{array}{l}94 / \cdot 0(40) \\
939 \cdot 1(28)\end{array}$ & $\begin{array}{ll}941 \cdot 1 & (112) \\
934 \cdot 3 & (56)\end{array}$ \\
\hline \multirow[t]{2}{*}{$M_{3}$} & $F$ & $819 \cdot 6$ & (36) & $828 \cdot 6(47)$ & $828.5(107)$ \\
\hline & $I$ & $845 \cdot 0$ & (8) & $813 \cdot 5(21)$ & $826 \cdot 0 \quad(53)$ \\
\hline \multicolumn{6}{|c|}{ Females } \\
\hline \multirow[t]{2}{*}{$M_{2}$} & $F$ & $953 \cdot 0$ & (18) & $935 \cdot 0(53)$ & $949.9(113)$ \\
\hline & $I$ & $959 \cdot 1$ & (12) & $948.9(33)$ & $940 \cdot 2 \quad(65)$ \\
\hline \multirow[t]{2}{*}{$\mathrm{M}_{3}$} & $F$ & $805 \cdot 5$ & (18) & $822 \cdot 2(48)$ & $838 \cdot 6(118)$ \\
\hline & $I$ & $845 \cdot 5 * *$ & (12) & $833.0(30)$ & $838.9 \quad(64)$ \\
\hline
\end{tabular}
Sample sizes are given in parentheses

for the combined sexes since in the original study some mice with only a single molar present (rather than both sides) were utilised. Because of this, the means (and variances) of the subsamples of mice used in this study do differ from those of the original study, although in most instances the differences are slight. Although the extent of sexual dimorphism in the means of both the $\mathrm{M}_{2}$ and $\mathrm{M}_{3}$ of these mice also is slight (Leamy and Bader, 1968), it did reach significance, and therefore the sexes are treated separately throughout the analysis. Among the wild mice of both sexes (table 1), the means of both teeth are larger in the infertile individuals although this trend reverses in the $F_{1}$ generation for males, and in the $F_{2}$ for females. In individual $t$ tests among the 12 fertile-infertile combinations, only that for the $M_{3}$ in wild females reached significance $(P<0 \cdot 01)$. There is a trend, 
although not a perfect one, in the fertile individuals for both molars (especially the $\mathrm{M}_{3}$ ) to increase throughout the three generations, whereas in the infertile mice, molar means generally decrease.

Least-squares analyses of variance of both molars in the separate sexes, the results from which are given in table 2, confirm that the only overall significant fertility difference between means is in the $\mathrm{M}_{3}$ for females. Both

TABLE 2

\begin{tabular}{|c|c|c|c|c|}
\hline \multicolumn{5}{|c|}{ Analyses of variance of the $M_{2}$ and $M_{3}$ for each sex } \\
\hline & Source & d.f. & M.S. $-M_{2}$ & M.S. $-\mathrm{M}_{3}$ \\
\hline Males & $\begin{array}{l}\text { Fertility }(F) \\
\text { Generations }(G) \\
F \times G \\
\text { Error }\end{array}$ & $\begin{array}{r}1 \\
2 \\
2 \\
282,266\end{array}$ & $\begin{array}{r}10 \cdot 7 \\
2087 \cdot 1 \\
1501 \cdot 6 \\
1459 \cdot 4\end{array}$ & $\begin{array}{r}264 \cdot 5 \\
1314 \cdot 3 \\
3675 \cdot 3 \\
1390 \cdot 4\end{array}$ \\
\hline Females & $\begin{array}{l}\text { Fertility }(F) \\
\text { Generations }(G) \\
F \times G \\
\text { Error }\end{array}$ & $\begin{array}{r}1 \\
2 \\
2 \\
288,284\end{array}$ & $\begin{array}{l}387 \cdot 7 \\
2016 \cdot 1 \\
3916 \cdot 2 * \\
1132 \cdot 3\end{array}$ & $\begin{array}{c}11866 \cdot 7^{* *} \\
4580 \cdot 5^{*} \\
5050 \cdot 7^{*} \\
1275 \cdot 9\end{array}$ \\
\hline
\end{tabular}

molars in females also exhibit a significant fertility-generation interaction, but none of the sources of variation for males reaches significance. Detectable directional selection, then, would seem to be limited to one sex, molar, and generation.

\section{TABLE 3}

$M_{2}$ and $M_{3}$ variances for fertile $(\mathrm{F})$ and infertile (I) individuals over each of the separate generations, and for all three generations (pooled values). Sample sizes are the same as in table I

\begin{tabular}{|c|c|c|c|c|c|}
\hline Males & & $W$ & $F_{1}$ & $F_{2}$ & $\begin{array}{c}\text { Pooled } \\
\text { generations }\end{array}$ \\
\hline \multirow{2}{*}{$\mathbf{M}_{2}$} & $F$ & $1247 \cdot 8$ & $1361 \cdot 7$ & $1398 \cdot 6$ & $1361 \cdot 7$ \\
\hline & $I$ & $1845 \cdot 1$ & 1733.0 & $1610 \cdot 2$ & $1667 \cdot 9$ \\
\hline \multirow{2}{*}{$\mathbf{M}_{3}$} & $F$ & 1032.5 & $1362 \cdot 0$ & $1220 \cdot 8$ & $1220 \cdot 3$ \\
\hline & $I$ & 1347.0 & $1860 \cdot 3$ & $1807 \cdot 5 *$ & $1780 \cdot 1^{*}$ \\
\hline \multicolumn{6}{|l|}{ Females } \\
\hline \multirow[t]{2}{*}{$\mathbf{M}_{2}$} & $F$ & $865 \cdot 3$ & $942 \cdot 8$ & $1032 \cdot 5$ & $991 \cdot 0$ \\
\hline & $I$ & $622 \cdot 0$ & $1628 \cdot 5^{*}$ & $1371 \cdot 7$ & $13714^{*}$ \\
\hline \multirow[t]{3}{*}{$\mathrm{M}_{3}$} & $F$ & $1164 \cdot 1$ & $782 \cdot 9$ & $1388 \cdot 2$ & $1210 \cdot 0$ \\
\hline & $I$ & $904 \cdot 4$ & $1196 \cdot 5$ & $1563 \cdot 3$ & $1389 \cdot 7$ \\
\hline & & & $\mathrm{P}$ & & \\
\hline
\end{tabular}

The situation for the variances (table 3 ) is somewhat different. Although only two of the 12 comparisons of variances reached significance in individual (one-tailed) $\mathrm{F}$ tests, the overall tendency clearly is for the variances of the infertile individuals to be greater than those for the fertile individuals (stabilising selection). The exception to this occurs in the wild females 
where destabilising selection (though not significant) is present for both molars. Bartlett's test revealed no significant differences $(P>0.05)$ among the variances in either molar or sex throughout the three generations, so pooled values are also included in the table. Two $\left(\mathbf{M}_{3}\right.$ in males, $\mathbf{M}_{2}$ in females) of the four comparisons of these pooled values show significant $(\mathrm{P}<0.05) \mathrm{F}$ tests, and that for the $\mathrm{M}_{2}$ in males generates a fairly low probability ( $P=0 \cdot 12$ ).

Comparison of variances among the six combinations of fertility and generations in each molar and sex was also accomplished by a statistical test recently devised by Grant and Herr (1975). Essentially this test involves subdividing each of the cells into subsamples of not less than three, calculating

\section{TABLE 4}

$M_{2}-M_{3}$ correlation coefficients for fertile (F) and infertile (1) mice in each of the three generations, and over all generations (pooled values). Sample sizes are given in parentheses

\begin{tabular}{ccccc} 
& & \multicolumn{1}{c}{} & $\begin{array}{c}\text { Pooled } \\
\text { generations }\end{array}$ \\
Males & $W$ & $\mathrm{~F}_{1}$ & $\mathrm{~F}_{2}$ & \\
$F$ & $0.573(36)$ & $0.642(44)$ & $0.726(107)$ & 0.683 \\
$I$ & $0.944^{*}(9)$ & $0.745(20)$ & $0.761(51)$ & 0.784 \\
& & & \\
Females & $0.253(16)$ & $0.606(47)$ & $0.484(111)$ & 0.503 \\
$F$ & $0.528(11)$ & $0.633(30)$ & $0.691^{*}(61)$ & 0.663 \\
$I$ & & $*$ & $\mathrm{P}<0.05$.
\end{tabular}

the $\log$ of the variance of each subsample, and then performing a standard analysis of variance on these transformed values. Because of the unequal numbers of variates per cell in the present data, resort was made to a stepwise regression programme in which fertility was "forced" in as the first variable (Herr, personal communication). The only significant M.S. in the two-way analyses of variance was for generations in the $\mathrm{M}_{3}$ for males, but the fertility category for both molars in males nearly reached significance $(P=0.07$ in both cases $)$. The fertility $\times$ generation interaction for both molars in females also was close to significance $(P=0.08$ and 0.09$)$, presumably because of the reversal of the variance pattern from $W$ to the $\mathrm{F}_{1}$ and $\mathrm{F}_{2}$ generations. These results seem sufficiently similar to the above to offer a corroboration of the overall tendency towards stabilising selection.

Correlation coefficients between the $M_{2}$ and $M_{3}$ widths for the fertile and infertile individuals of each sex throughout the three generations are presented in table 4. Sample sizes also are included since in some combinations there is a slight reduction from the numbers previously given (table 1). The most obvious feature of these data is that the correlations for the infertile mice exceed those for the fertile mice in all six instances, two of the comparisons reaching statistical significance $(P<0 \cdot 05)$. Even the wild females exhibit this pattern, and since they previously showed destabilising selection (table 3), this suggests that the correlation trend is not merely a consequence of the variance differences. Correlations for each of the four combinations of sex and fertility showed no significant differences through the three generations (in $\chi^{2}$ tests, $\mathrm{P}>0.05$ ), so that pooled values also are given. The difference between the fertile and infertile individuals is even 
more nicely shown by these pooled values, although neither comparison quite makes statistical significance $(P=0.10$ and 0.052 , respectively, for the males and females). Another feature of these data, again especially apparent in the pooled values, is that males exhibit higher correlations than females.

Estimates of the intensities $(I)$ of selection, and the change in mean relative fitness $(\Delta \bar{w} / \bar{w})$ for each combination of sex, age and molar are given in table 5. O'Donald's (1968, 1970a) expressions (1) and (2) previously explained were used in all cases except that for the wild females. Since

TABLE 5

Estimates of the intensity of selection $(\mathbf{I})$ and the change in mean relative fitness $(\Delta \bar{w} / \bar{w})$ using fertility as the criterion of selection for the $M_{2}$ and $M_{3}$ in male and female mice of each of the three generations

\begin{tabular}{|c|c|c|c|c|}
\hline Males & & $W$ & $F_{1}$ & $\mathrm{~F}_{2}$ \\
\hline $\mathrm{M}_{2}$ & $\Delta \bar{w} / \bar{w}$ & $\begin{array}{l}0.060 \\
0.008\end{array}$ & $\begin{array}{l}0.070 \\
0.009\end{array}$ & $\begin{array}{l}0.059 \\
0.004\end{array}$ \\
\hline $\mathbf{M}_{3}$ & $\underset{\Delta \bar{w} / \bar{w}}{I}$ & $\begin{array}{l}0.136 \\
0.020\end{array}$ & $\begin{array}{l}0.177 \\
0.015\end{array}$ & $\begin{array}{l}0.061 \\
0.008\end{array}$ \\
\hline $\begin{array}{c}\text { Females } \\
\qquad \mathbf{M}_{2}\end{array}$ & $\underset{\Delta \vec{w} / \bar{w}}{I}$ & $\overrightarrow{0.008}$ & $\begin{array}{l}0 \cdot 113 \\
0 \cdot 033\end{array}$ & $\begin{array}{l}0 \cdot 114 \\
0.022\end{array}$ \\
\hline $\mathbf{M}_{3}$ & $\Delta \bar{w} / \bar{w}$ & $\overline{0.196}$ & $\begin{array}{l}0 \cdot 136 \\
0 \cdot 037\end{array}$ & $\begin{array}{l}0.016 \\
0.001\end{array}$ \\
\hline
\end{tabular}

stabilising selection did not occur here, only $\Delta \bar{w} / \bar{w}$ from (3) was calculated. In all instances the pooled fertile and infertile individuals were taken to represent the "before selection" populations whereas the fertile individuals were used as the "after selection" populations.

The intensities of selection (table 5) range from 0.02 to 0.18 with an overall mean level of nearly $0 \cdot 1$. Most of the $\Delta \bar{w} / \bar{w}$ values are considerably (but typically) lower than the intensities, the only exception being that for the $\mathrm{M}_{3}$ in wild females. It will be recalled that this was the only combination which showed a significant $(P<0.01)$ difference between fertile and infertile means (table 1), this large difference generating the very high value $(0.20)$ for $\Delta \bar{w} / \bar{w}$. There are two apparent, although not perfect, trends in the $I$ and $\Delta \bar{w} / \bar{w}$ values: they tend to decrease through the three generations, and they are generally higher for the $\mathbf{M}_{3}$ than for the $\mathbf{M}_{2}$. In other words, selection is more stringent on the wild mice, relaxing somewhat in the laboratory, and the $\mathrm{M}_{3}$ more than the $\mathrm{M}_{2}$ seems to be the focus of this selection.

\section{Discussion}

The results of the present analysis clearly indicate that selection via differential fertility, previously detected (Leamy and Bader, 1970) in the Peromyscus populations, is exerting an appreciable force on the molar widths. Fertility itself was assessed in an all-or-none fashion (mandated by both theoretical and practical considerations) within generations, and therefore the estimates of selection intensity are of course applicable only to a part of 
the total selection cycle (Prout, 1969). Net selection effects on the molars between generations could not even be assessed both because selection decreased throughout the three generations, and since theoretically the heritabilities of both molars would have to be 1 for any such estimations across generations (O'Donald, 1968).

Although the heritabilities of the widths of both molars obviously were not 1 , they were rather high $(0.6$ overall $)$, increasing from 0 in the first generation to about 0.8 by the third generation (Leamy and Bader, 1968). Some increase would be expected from the relaxation of selection during the three generations, although not one nearly of this magnitude (Scharloo, 1964; Scharloo et al., 1967). The low heritabilities in the first generation very likely are under-assessments caused by the presence of a genotypeenvironmental interaction between natural and laboratory environments. Full-sib intraclass correlations calculated for this generation only, in fact, imply heritabilities of $0.6\left(\mathrm{M}_{2}\right)$ and $0.5\left(\mathrm{M}_{3}\right)$. A good part of the increase from these levels to the final one of 0.8 probably can be accounted for by the uniform laboratory environment in which the mice were reared, so that overall it must be concluded that the genetic variance of both molars was consistently high throughout the three generations.

Since the fertility mean square in the analysis of variance reached significance for the $\mathrm{M}_{3}$ in wild females (and nearly also did for the same comparison in males), directional selection does seem to be present in the wild mice for at least this molar. However, the $\Delta \bar{w} / \bar{w}$ value of $0 \cdot 196$ for the wild females undoubtedly is inflated as a result of the small sample sizes involved, and if the sexes are pooled, the new combined $\Delta \bar{w} / \bar{w}$ value decreases to a more credible 0.044. Sampling error in these same wild females also may have caused the greater variances (for both molars) in fertile compared with infertile individuals whereas all other combinations exhibited the opposite trend (stabilising selection). Presumably also, the mice trapped from the wild had already experienced a period of stringent natural selection via mortality, and thus the survivors (both fertile and infertile) might be expected to exhibit less variability than individuals in subsequent laboratory generations.

The mean level of intensity of the selection on the Peromyscus molar widths was $0 \cdot 10$, implying that fitness would be increased by $I /(1-I)=$ 11 per cent if all individuals were at the optimal (molar width) value (O'Donald, 1970a). The mean $\Delta \bar{w} / \bar{w}$ value of 0.02 (calculated in part using the value of 0.044 above), however, is somewhat more useful in that it describes the percentage increase ( 2 per cent) in fitness which actually has been realised as a result of selection. In so far as is known, this is the first time such estimates utilising this criterion (mating success versus failure) of selection have been made for any quantitative character, but a number of estimates derived from other criteria are available for comparison. For example, O'Donald $(1970 a$ ) calculated an $I$ value of 0.09 for molar widths from young versus old rats (Van Valen and Weiss, 1966), and an $I$ value of $0.12(\Delta \bar{w} / \bar{w}=0.10)$ for selection acting on the number of Arctic Skua chicks fledged from different clutch sizes (O'Donald, 1972). Other values are summarised in Johnson (1976), and although the validity of all such comparisons is necessarily limited, they do suggest that the general level of selection on the Peromyscus molars is impressively high for differences generated only from differential fertility. 
It is difficult to imagine a functional reason why selection via fertility of this intensity would be directly concerned with altering characters such as molar widths. It seems far more plausible to postulate, as was done previously (Leamy and Bader, 1970), that selection is instead operating on some character such as body size to which molar widths are pleiotropically related. Although in the present case this hypothesis cannot be tested, intermediate-sized individuals of several species often have been found to be physiologically best suited for mating (see Scheiring, 1977, for a recent example). The high heritability of both molars also argues against their direct involvement with selection, although the expected reduction of the genetic variance of these characters is less if the number of loci governing the characters is great (Crow and Kimura, 1970; Bulmer, 1971). None the less, eventual fixation of genes is the result of stabilising selection provided that fitness is determined by the deviation of individuals from the mean (Robertson, 1956). However, if extreme deviates are selected against because they are more homozygous (homeostatic model) genetic variation is maintained (Robertson, 1956). Actually this homeestatic model was previously invoked (Leamy and Bader, 1970) for both molars (because their predominantly statistically additive genetic variance implied classical additivity as well), but of course any such interpretation of the cause of this selection must remain speculative.

The consistent pattern of differences in the magnitude of the $M_{2}-M_{3}$ correlations between the fertile and infertile individuals fits quite well some theoretical predictions made by Van Valen (1962). In a study involving the lengths and widths of all six pairs of molars in a population of Peromyscus leucopus, Van Valen (1962) was able to deduce the presence of a factor (perhaps the amount of substance available for development of the dental lamina) which limits the length of the total tooth row to some optimal intermediate value. Further, since the dental correlations he observed showed the relative independence of the late-developing third molars (M3s) from the first two anterior molars, presumably these M3s (both upper and lower) would bear the brunt of such accommodation to the optimal value or range. If the limiting factor is assumed to be stabilising selection, individuals whose M2 and M3 widths are both large, or both small, would be selected against, and they would therefore exhibit higher interdental correlations than those individuals selected for (Van Valen, 1962). This, of course, is precisely the direction of the pattern exhibited by the fertile and infertile Peromyscus, and although other explanations are possible, this hypothesis does seem most plausible. Another implication of this hypothesis, incidentally, is that the intensity of any such selection on the molars should be greater for the M3s than for the M2s, against exactly as was found in this study.

Acknowledgments.-I am extremely grateful to Dr Robert S. Bader for the original inspiration for this study, to Drs Russell Lande, Robert Clover, and David Huckaby, and two anonymous reviewers for critically reading the manuscript and making valuable suggestions for its improvement, and to David Bradley of the University Data Processing Center for computer assistance.

\section{REFERENCES}

BULMER, M. G. 1971. The effect of selection on genetic variability. Amer. Nat., 105, 201-211. Grow, J. F., AND kimura, M. 1970. An Introduction to Population Genetics Theory. Harper and Row, New York.

$41 / 1-\mathrm{C}$ 
FISHER, R. A. 1930. The Genetical Theory of Natural Selection. Glarendon Press, Oxford. GRANT, M. C., AND HERR, D. G. 1975. Simultaneous comparison of population variances-A special technique. Genetics, 80, s36.

haldane, J. B. s. 1954. The measurement of natural selection. Proc. IX Int. Cong. Genet., $1,480-487$.

Jounson, C. 1976. Introduction to Natural Selection. University Park Press, Baltimore.

LEAMY, L. J., AND BADER, R. s. 1968. Components of variance of odontometric traits in a wild-derived population of Peromyscus leucopus. Evolution, 22, 824-834.

LEAMY, L. J., AND BADER, R. s. 1970. Stabilising selection for odontometric traits in Peromyscus leucopus. Amer. Midl. Nat., 84, 521-536.

MARCus, L. F. 1964. Measurement of natural selection in natural populations. Nature, Lond., 202, 1033-1034.

o'donald, P. 1968. Measuring the intensity of natural selection. Nature, Lond., 220, 197-198.

o'DonALD, P. 1970a. Measuring the change of population fitness by natural selection. Nature, Lond., 227, 307-308.

o'Donald, P. 1970b. Change of fitness by selection for a quantitative character. Theor. Pop. Biol., 1, 219-232.

o'DonALD, P. 1971. Natural selection for quantitative characters. Heredity, 27, 137-153.

o'DoNALD, P. 1972. Natural selection of reproductive rates and breeding times and its effect on sexual selection. American. Nat., 106, 368-379.

o'Donald, P. 1973. A further analysis of Bumpus' data: The intensity of natural selection. Evolution, 27, 398-404.

Prout, T. 1969. The estimation of fitnesses from population data. Genetics, 63, 949-967. ROBERTSON, A. 1956. The effect of selection against extreme deviants based on deviation or on homozygosis. 7. Genet., 56, 236-248.

scharloo, w. 1964. The effect of disruptive and stabilising selection on a cubitus interruptus mutant in Drosophila. Genetics, 50, 553-562.

SCHARLOo, w., hOOGMOED, M. S., AND TERKUILE, A. 1967. Stabilising and disruptive selection on a mutant character in Drosophila. I. The phenotypic variance and its components. Genetics, 56, 709-726.

SCHEIRING, J. F. 1977. Stabilising selection for size as related to mating fitness in Tetraopes. Evolution, 31, 447-449.

van valen, L. 1962. Growth fields in the dentition of Peromyscus. Evolution, 16, 272-277.

VAN VALEN, L. 1963. Selection in natural populations: Merychippus primus, a fossil horse. Nature, Lond., 197, 1181-1183.

van valen, L. 1965a. Selection in natural populations. III. Measurement and estimation. Evolution, 19, 514-528.

van valen, L. 1965b. Selection in natural populations. IV. British housemice (Mus musculus). Genetica, 36, 119-134.

VAN VALEN, L. 1967. Selection in natural populations. 6. Variation genetics, and more graphs for estimation. Evolution, 21, 402-406.

VAN VALEN, L., AND WEISS, R. 1966. Selection in natural populations. V. Indian rats (Rattus rattus). Genet. Res., Camb., 8, 261-267. 